\title{
Una historia de la política
} migratoria guatemalteca de 1980
a los primeros años del siglo XXI

A History of GuATEMALA's MIGRATION POLICY FROM 1980 TO THE EARLY YEARS OF THE XXI CENTURY

\author{
Ian Yetlanezi Chávez-Flores*
}

* Universidad Autónoma del Estado de México, México Correo-e: letrasian@gmail.com Recibido: 28 de enero de 2020 Aprobado: 18 de junio de 2020

Resumen: Se realiza una sistematización histórica de los diversos planes, programas y acciones que ha implementado el gobierno guatemalteco para respetar los derechos humanos y, a su vez, hacer de la migración y el retorno a su país procesos voluntarios y seguros. Se analizan tres periodos diferentes: la década de los ochenta, la década de los noventa y el tercer lustro del siglo XXI. Se hace énfasis en la participación de diversos actores gubernamentales, organismos internacionales, naciones centroamericanas y asociaciones civiles en el resarcimiento de los daños causados por la guerra civil, el establecimiento de un Estado democrático, la aplicación de la justicia y la búsqueda de paz y estándares de bienestar básicos para la población.

Palabras clave: historia latinoamericana; historia social; investigación histórica; Guatemala; memoria colectiva; guerra civil; violación de los derechos humanos; refugiado; política migratoria; seguridad humana

Abstract: A historic systematization of the various plans, programs and actions implemented by Guatemalan government in order to make migration from and returns to the country safe and voluntary, respecting at once human rights. Three different periods are analyzed: the 1980's, 90's and the third lustrum of the XXI century. Emphasis is made on the participation of several governmental actors, international agencies, Central American nations and civil associations in repairing the havoc wreaked by the civil war, the establishment of a democratic State, fair justice administration, peacekeeping and basic wellbeing population standards.

Keywords: Latin American history; social history; historical research; Guatemala; collective memory; civil war; human rights violations; refugees; migration policy; human security 


\section{INTRODUCCIÓN}

La sistematización de las acciones, programas y planes que a lo largo del tiempo se han implementado en Guatemala para hacer de la emigración y el retorno procesos voluntarios y con respeto a los derechos humanos, ha sido documentada de manera breve, general y se encuentra esparcida en fuentes específicas (Castillo, 2000: 147).

Esto se debe a que las problemáticas sociales, económicas y climáticas que han existido en el país centroamericano son tan amplias, que las delimitaciones de los trabajos de investigación se basan en temporalidades específicas y en estudios sociales muy concretos que entregan un panorama general de dichos eventos. Aunque contar con registros claros es un avance muy importante en la investigación de las ciencias sociales y las humanidades, muy pocos análisis han abordado esta temática de una manera profunda que, a su vez, permita ofrecer una visión histórica y continua de la problemática.

Por tal motivo, el Marco general y descripción de acciones del Estado de Guatemala en materia migratoria (2010), de Erick Mauricio Maldonado Ríos - exsecretario ejecutivo del Consejo Nacional de Atención al Migrante de Guatemala (CONAMIGUA) - , es un documento de suma relevancia, ya que otorga una perspectiva histórica de las diversas acciones políticas que los gobiernos han implementado para resarcir los daños que los conflictos armados internos ocasionaron en las últimas décadas del siglo XX. De igual manera, en este texto se encuentra una breve y concisa descripción de algunas medidas en materia migratoria aplicadas durante los primeros dos lustros del siglo XXI.

En este sentido, el trabajo de Maldonado Ríos funciona como una guía para nuestra investigación. Con los datos de este documento profundizamos en la complejidad del tema y sistematizamos de manera histórica las acciones, planes y programas que se han llevado a cabo en Guatemala durante 36 años.

Para lograr el objetivo planteado, se revisó y analizó bibliografía producida por investigadores, periodistas y asociaciones civiles. El libro Politicas sobre la historia en Guatemala. Historiografia, justicia de posguerra y resarcimiento (1996-2005) (2014), de Berthold Molden, constituye una pieza clave en este trabajo, pues entrega una interesantísima historia crítica que contribuye a la narración de voces de diferentes actores sociales que, a su vez, revelan las preocupaciones de una sociedad que intenta resarcir los daños de la guerra civil.

Otro elemento importante para la elaboración de este artículo es el análisis de las diversas gestiones que han realizado las asociaciones civiles respecto a la situación migratoria en este país, poniendo especial atención en la Organización de Mujeres Guatemaltecas Mamá Maquín, la Mesa Nacional para las Migraciones en Guatemala (MENAMIG) y el Instituto Centroamericano de Estudios Sociales y Desarrollo (INCEDES).

Con estas fuentes, se reordenó la información de diferentes periodos para establecer temporalidades que permitan visualizar y analizar las disposiciones que se han efectuado durante dicho periodo. De esta manera, se aborda el tema por medio de décadas, empezando con los años ochenta del siglo XX, y terminando con la segunda década del siglo XXI.

\section{Guatemala, DÉcADA DE 1980}

A principios de la década de 1980, los enfrentamientos entre el ejército y los grupos guerrilleros se volvieron más violentos e involucraron a la sociedad civil, principalmente campesinos y personas que vivían en condiciones de pobreza en el altiplano noroccidental. En consecuencia, ocurrieron dos cosas: 
1. La población que no estaba implicada en estos conflictos decidió salir de sus comunidades y dirigirse a otras partes de su país o, incluso, buscaron refugio en otra nación. Muchos emigraron a México para salvaguardar su vida.

2. "El gobierno militar del general Fernando Romeo Lucas García, en un intento por acabar con los movimientos armados contrarios a su régimen, implementó la política conocida como Tierra Arrasada, que tenía como objetivo eliminar a poblaciones enteras que se pensaba brindaban apoyo a la guerrilla” (Pérez Mendoza, 2016: 189-190).

La Comisión para el Esclarecimiento Histórico (CEH) (1999: 285) señala que, durante los primeros años de esta década, los resultados del conflicto armado interno fueron alarmantes, pues se registraron 35000 muertos, 45000 refugiados en el exterior, 1200000 desplazados internos, así como más de 200000 huérfanos y 40000 viudas. ${ }^{1}$ Durante la guerra civil, la preocupación del gobierno guatemalteco fue mantener el control y el orden, sin importar la protección a los derechos humanos. Las presiones políticas, económicas, sociales, psicológicas, civiles y éticas que existían en el país centroamericano obligaron a ciertas comunidades a salir de su país sin saber cuándo iban a volver.

Ante esta situación, en 1983, los gobiernos de Colombia, México, Panamá y Venezuela crearon el Grupo Contadora para promover la paz en Centroamérica. Los cancilleres centroamericanos adoptaron una serie de objetivos en la ciudad homónima de Panamá.

El documento declara la voluntad de los gobiernos centroamericanos de promover la democratización y terminar los conflictos armados,

1 Estas cifras son similares a las que reportó Fernández (1991: 21), quien indicó que en dicho conflicto social se registraron más de 40000 muertos, miles de desaparecidos, 100000 huérfanos, 1000000 de personas que se desplazaron dentro de Guatemala y 300000 refugiados en el exterior. actuando de acuerdo al Derecho internacional, para revitalizar y restaurar el desarrollo económico y la cooperación en Centroamérica, y negociar mejores accesos a los mercados internacionales (Grupo Contadora, 1986).

A pesar de que esta colaboración multilateral tuvo como objetivo establecer la paz en la región, no se logró de manera aceptable. Sin embargo, el Grupo Contadora sentó las bases históricas para formular y aplicar estrategias que tuvieron como fin terminar con el conflicto armado interno, instaurar la democratización del Estado guatemalteco e implantar una paz aceptada por las comunidades que integran esta nación.

Con este antecedente, en 1986, ocurrieron dos eventos importantes:

1) En enero, el presidente Vinicio Cerezo Arévalo invitó a los mandatarios de todas las naciones centroamericanas a discutir y analizar la situación sociopolítica de la región. La reunión se llevó a cabo en la ciudad de Esquipulas, Guatemala, y asistieron la mayoría de los invitados, ${ }^{2}$ con excepción del presidente de Costa Rica, Luis Alberto Monge Álvarez, quien declaró estar enfermo. En este encuentro, los dignatarios:

$$
\begin{aligned}
& \text { firmaron una declaración de respaldo a las ges- } \\
& \text { tiones del Grupo Contadora, así como el interés } \\
& \text { de continuar discutiendo conjuntamente los } \\
& \text { problemas de la región y aceptando para ello la } \\
& \text { invitación formulada por el Presidente Cerezo, } \\
& \text { para reunirse en la ciudad de Esquipulas, Gua- } \\
& \text { temala (Soberanis y Chamorro Marín, 2016). }
\end{aligned}
$$

En mayo, todos los presidentes de la región centroamericana volvieron a reunirse para elaborar de manera conjunta la Declaración de Esquipulas I. En este importante documento se reconoce que, para brindar la paz e instaurar la

2 Los presidentes que asistieron fueron: Daniel Ortega Saavedra, de Nicaragua; José Napoleón Duarte, de El Salvador; José Azcona Hoyo, de Honduras; Erick Arturo del Valle, de Panamá; y Vinicio Cerezo Arévalo, de Guatemala. 
democratización en las diferentes naciones, es necesario continuar con "el Proceso Contadora creado gracias al esfuerzo de algunos países latinoamericanos y reconocido por la comunidad internacional" (Arias Sánchez, Cerezo Arévalo, Duarte et al., 1986: 1). Asimismo, en el punto 4 de esta declaración, se enfatiza que:

la paz en América Central sólo puede ser fruto de un auténtico proceso democrático pluralista y participativo que implique la promoción de la justicia social, el respeto a los derechos humanos, la soberanía e integridad territorial de los Estados y el derecho de todas las naciones a determinar libremente y sin injerencias externas de ninguna clase, su modelo económico, político y social, entendiéndose esta determinación como el producto de la voluntad libremente expresada por los pueblos (Arias Sánchez, Cerezo Arévalo, Duarte et al., 1986: 3).

Este importante avance político dio pie a una siguiente reunión el 7 de agosto de 1987, que fue denominada Esquipulas II. En esta junta se elaboró un documento que:

expresaba la decisión política de los gobernantes centroamericanos, de que sus sociedades nacionales se apropiasen realmente del proceso de democratización y pacificación en el área y ha sido considerada como un Pacto político que deriva su legitimidad de la representación nacional con la cual actuaron los Presidentes (Soberanis y Chamorro Marín, 2016).

Tanto las acciones políticas del Grupo Contadora como las declaraciones de Esquipulas I y II sirvieron como antecedente para que se le diera continuidad a la problemática hasta la década de 1990, específicamente, hasta la firma de los Acuerdos de Paz de Guatemala en 1996.

2) El presidente Vinicio Cerezo invitó a los refugiados guatemaltecos a regresar a su país, garantizando el respeto íntegro e irrestricto a sus derechos humanos para así, de manera conjunta, lograr la paz. No obstante, la respuesta fue una negativa; los argumentos de esta decisión se redactaron en una carta que se le hizo llegar al gobierno. En ella se mencionaba que los migrantes no volverían porque:

no hay respeto de los derechos humanos; no hay libertad de expresión; continúan las organizaciones paramilitares; continúa el hambre y la miseria para la mayoría de la población; continúan las patrullas civiles, polo de desarrollo y aldeas modelos, donde la gente es concentrada por la fuerza (Fernández, 1991: 35).

Los esfuerzos de Cerezo no terminaron ahí. En abril de 1987, el mandatario invitó al presidente mexicano Miguel de la Madrid a la ciudad de Antigua para firmar el Convenio de Repatriación de Refugiados Guatemaltecos. Vinicio Cerezo mencionó que sus compatriotas podían regresar a su país "con la garantía plena del goce de los derechos generales de los ciudadanos" (Proceso, 2002). De igual manera, se comprometió a "garantizar su libre establecimiento y circulación en su territorio, así como a reconocerles sus propiedades individuales o colectivas o, en su caso, restituírselas y, además, hacer voluntaria su participación en las patrullas de autodefensa civil" (Proceso, 2002).

La respuesta que obtuvo fue similar a la de 1986. Sin embargo, en 1987, las comunidades de guatemaltecos acogidas en México se organizaron y crearon las Comisiones Permanentes de Representantes de los Refugiados (CCPP). La instauración de estas organizaciones permitió dar voz a quienes habían emigrado por diversos motivos, principalmente, la inseguridad causada por los conflictos armados internos. Además, las CCPP podían "participar en el Diálogo Nacional de su país, con voz y voto en las deliberaciones por reunir los requisitos de legalidad, legitimidad y representatividad" (Fernández, 1991: 36). 
De esta manera, las CCPP dieron a conocer su opinión - a nivel nacional e internacionalacerca de las condiciones que necesitaban las personas para hacer efectiva su reintegración en la sociedad guatemalteca. José Manuel Fernández expone seis principales:

1) El retorno tenía que ser una decisión voluntaria, expresada individualmente, pero debía llevarse a cabo en forma colectiva y organizada, en condiciones de seguridad y dignidad.

2) Garantía de que no se impediría el retorno a sus tierras y a tomar posesión de ellas.

3) Reconocimiento del derecho a organizarse y asociarse libremente.

4) Garantía del derecho a la vida e integridad personal y comunitaria.

5) Que el gobierno de Guatemala permitiera que el retorno fuera acompañado de delegaciones nacionales e internacionales, de organizaciones no gubernamentales y de representantes del Alto Comisionado de las Naciones Unidas para los Refugiados (ACNUR).

6) Garantía de la libre movilización nacional e internacional de los miembros de las CCPP, así como de los retornados (1991: 136).

Las condiciones arriba citadas continuaron siendo exigidas durante la primera parte de la siguiente década.

\section{Guatemala, dÉCADA DE 1990}

La población guatemalteca que se asentaba en los campamentos de Chiapas, Tabasco y Quintana Roo, en México, comenzó a manifestar una conciencia y posición política con respecto a su estatus de refugiada. Ejemplo de ello fue la creación de la Organización de Mujeres Guatemaltecas Mamá Maquín en 1990. El nombre de este organismo surgió en honor a la lideresa Adelina Caal, quien en 1978 "encabeza una marcha en Panzós en reclamo de tierras para los campesinos, durante el gobierno del presidente Kjiell Eugenio Laugerud García. Es reprimida por el Ejército de Guatemala. Fue una de las 52 personas asesinadas" (Archilla, 2015).

El objetivo de la agrupación era "organizar a las mujeres de cara a un retorno digno en el marco de los seis puntos propuestos por las Comisiones Permanentes de Representantes de los Refugiados” (Fernández, 1991: 36). Además, proponía alfabetizar a los migrantes para que pudieran defender sus derechos cuando regresaran a su país. Cabe destacar que esta iniciativa fue de suma importancia porque proponía un retorno cultural. Es decir, no sólo volverían físicamente a su patria, sino que enseñarían a las niñas y niños su pertenencia histórica a algunas regiones indígenas de la nación centroamericana, así como sus códigos morales y éticos, con el fin de que se identificaran y sintieran orgullo del vestuario indígena. Con ello, existiría una pertenencia cultural hacia sus comunidades (Archilla, 2015; Fernández, 1991: 37).

Esta organización fue tan exitosa que, en 1991, había cerca de 6000 miembros guatemaltecos en los diversos campamentos de la frontera sur mexicana. Además, fue un pilar fundamental para coordinar el retorno de la población refugiada a Guatemala:

Durante su II Asamblea General, celebrada el 15 de agosto de 1991, Mamá Maquín propuso los siguientes objetivos para el año 19911992: crear la infraestructura y los equipos de trabajo para hacer llegar a las bases los comunicados de la organización y los documentos del movimiento popular y sindical en Guatemala; apoyar la lucha por el retorno liderada por las Comisiones Permanentes de Refugiados; defender la cultura del pueblo indígena; fortalecer las relaciones con el movimiento sindical y popular; y fomentar la participación de Mamá Maquín en eventos nacionales e internacionales (Fernández, 1991: 37). 
La organización de la población refugiada dejó en claro que su participación era un proyecto político que definía las condiciones bajo las cuales querían regresar a su país. De esta manera, el 8 de octubre de 1992 se firmaron los acuerdos donde se definían las bases, condiciones y garantías del retorno, las cuales contenían parte de las seis propuestas de las CCPP y la Organización de Mujeres Guatemaltecas Mamá Maquín (Kauffer Michel, 2000: 10).

La primera repatriación se llevó a cabo el 20 de enero de 1993. Sin embargo, una parte de los refugiados guatemaltecos no deseaba volver porque se había acostumbrado a vivir en México. Además, el regreso se asociaba con la idea de comenzar de cero, conjuntamente con los recuerdos asociados a la violencia e inseguridad. Es decir, algunas personas encontraban mejores condiciones de vida en el país de acogida (Kauffer Michel, 2000: 11).

Armijo Canto (2011: 39) señala que algunos de quienes decidieron retornar a su patria no encontraron condiciones dignas que les permitieran reconstruir su vida, por lo que decidieron volver al país donde se refugiaron. Esto, según Bornschein (2017), muestra cómo el Estado guatemalteco - a pesar de los esfuerzos por regresar a los compatriotas que fueron expulsados de manera forzada por los conflictos armados internos- no contaba con una organización adecuada para el recibimiento de sus connacionales, como tampoco con instituciones fuertes que permitieran el desarrollo de la población en todos los niveles de bienestar.

La debilidad de las instituciones guatemaltecas tenía su raíz en a los conflictos sociales históricos, aunque también era producto de la falta de capacidad política y democrática de sus gobernantes para resolver problemáticas estructurales y culturales. En 1993, el presidente Jorge Serrano Elías continuaba las negociaciones entre los grupos guerrilleros y los diversos sectores políticos con el fin de lograr la paz. Sin embargo, esto parecía más una simulación retórica, pues en ese año disolvió "ilegalmente el Congreso y la Corte Suprema de Justicia. Además trató de restringir las libertades civiles y políticas, aduciendo luchar contra la corrupción" (Monroy García, 2013: 84). Estas acciones estaban destinadas a un autogolpe de Estado, no obstante, Serrano Elías fracasó "debido a las protestas de la mayoría de la sociedad civil guatemalteca, la presión internacional, y la imposición del ejército sobre las decisiones del Tribunal de la Constitucionalidad, oponiéndose al intento de golpe de Estado" (Monroy García, 2013: 85).

En este sentido, en 1993, el retorno de las personas refugiadas en México se volvió una travesía, pues no existía un plan o programa para su reintegración. Sin embargo, en 1994, con la administración del presidente Ramiro de León Carpio, el gobierno guatemalteco decidió elaborar el primer boceto del Programa Nacional de Resarcimiento (PNR), donde se reconocía que su deber era subsanar y asistir a las personas que sufrieron violaciones a sus derechos humanos. A pesar de que este documento se quedó en una intención y no se concretó en acciones, debe reconocerse que fue un importante antecedente que sirvió en las futuras negociaciones de paz entre el gobierno y los grupos guerrilleros. Lamentablemente, el programa no se llevó a cabo porque "no era posible emprender un registro representativo de las víctimas mientras se seguían produciendo combates precisamente en las regiones más afectadas" (Molden, 2014: 196-197). Monroy García señala que:

\footnotetext{
bajo el gobierno de León Carpio, el proceso de paz cobró mayor impulso, apoyado también por las Naciones Unidas. A partir de 1994, la Organización de las Naciones Unidas (ONU) asumió el papel de mediador en el proceso pacificador entre la URNG y el gobierno de Guatemala (2013: 85).
}

Estas negociaciones fueron continuadas por el presidente Álvaro Enrique Arzú Irigoyen, quien 
el 29 de diciembre de 1996 firmó los Acuerdos de Paz con los grupos guerrilleros, principalmente con la Unidad Revolucionaria Nacional Guatemalteca (URNG). En este documento se reconocía la necesidad de hacer valer los derechos humanos de la población y también se hacía nuevamente la promesa — como ocurrió en 1994 con el boceto del PNR - de analizar los casos en que estos hubieran sido violados durante los conflictos armados internos, para así reconciliar a la población nacional con el gobierno y lograr una democratización del Estado. No obstante, Thesing argumenta que estos acuerdos sólo eran declaraciones con una voluntad política dirigida al discurso y a la retórica que no se llegaron implementar (1999: 29). ${ }^{3}$

A pesar de que este fue uno de los avances más importantes del presidente Álvaro Arzú, "su gobierno se caracterizó por la privatización de diversas empresas del Estado, entre las más importantes la eléctrica, los ferrocarriles, correos y la telefónica" (Monroy García, 2013: 86). Además, la inseguridad aumentó de manera considerable; el crimen que más se registró en este mandato fueron los secuestros. Cabe resaltar que Arzú había prometido respetar, entre otros principios, la libertad de expresión. No obstante, el 26 de abril de 1998, el obispo y activista Juan Gerardi Conedera fue asesinado después de publicar Guatemala. Nunca más, un informe donde recuperaba el recuento de las violaciones a los derechos humanos que sucedieron durante el conflicto armado interno:

3 El argumento de Thesing se encuentra muy bien contextualizado. Basta recordar la Masacre de Xamán, que ocurrió el 5 de octubre de 1995, cuando las Fuerzas Armadas presuntamente ejecutaron a 11 personas e hirieron a otras 29. Lo más alarmante fue que entre quienes perdieron la vida se incluían "una niña y dos niños, que formaban parte de la población indígena q'eqchi', mam, q'anjob'al, ixil y k'iche, que ocupaba la finca Xamán tras haber estado 'refugiada' en México" (CIDH, 2018: 4). Con este caso se observa que, en situaciones particulares, el gobierno guatemalteco no garantizaba a su población un retorno digno con respeto a los derechos humanos. La paz, la democratización y los ideales políticos en los que se fundamentan los instrumentos jurídicos son metas que aún deben trabajarse.
Guatemala. Nunca más, un informe de cuatro volúmenes y cuatrocientas páginas, elaborado por la REMHI, Recuperación de la Memoria Histórica, ${ }^{4}$ investigación sin precedente de las 'desapariciones', asesinatos, torturas y la violencia sistemática que se había infligido a la población de Guatemala desde inicios de los sesenta, cuando una serie de dictadores militares de derecha gobernaron el país y libraron una guerra contra los grupos guerrilleros de izquierda. Ese conflicto había concluido formalmente en diciembre de 1996, con los acuerdos de paz organizados por las Naciones Unidas. El informe identificaba por su nombre a más de 52 mil muertos y desaparecidos civiles durante la guerra, cuyo número se calculaba en 200 mil, y revelaba que el ejército de Guatemala y los grupos paramilitares asociados a éste habían cometido el 90\% de los crímenes, mientras que a las facciones guerrilleras correspondía poco menos del 5\%. El informe era minucioso y exhaustivo (Goldman, 1999).

Ante este complejo escenario, la población guatemalteca se enfrentó con diversas situaciones que la dejaban en una condición de vulnerabilidad, pues al privatizar empresas públicas y reducir el gasto social, el desempleo incrementó, se generó una inflación en los productos de la canasta básica y las acciones en detrimento de los derechos humanos continuaron. Algunos sectores de la sociedad decidieron salir de su nación para

4 Goldman explica como posible razón de este asesinato que el obispo Gerardi no estaba de acuerdo con una amnistía que permitía a diversos actores políticos y sociales evitar un posible enjuiciamiento por sus delitos: "La condición establecida para aceptar los acuerdos de paz por el ejército y la guerrilla era una amnistía general contra el enjuiciamiento por crímenes de guerra. Esto incendió a los activistas de los derechos humanos, que consideraron esa amnistía como una protección. El obispo Gerardi había fundado la REMHI en 1994, en parte porque dudaba que una comisión respaldada por la ONU para investigar la verdad tuviera fuerza suficiente ante el ejército. En realidad, el informe de la comisión de investigación de la verdad fue más allá que la REMHI al acusar de genocidio al ejército. Esto abrió la posibilidad de llevar a juicio a algunos oficiales, pues la amnistía no incluía los crímenes contra la humanidad" (1999). 
buscar mejores oportunidades de vida (Maldonado Ríos, 2010: 13; García Sánchez y Valdéz Rodas, 2002: 120).

A su vez, el Estado reconoció que durante esta década incrementó la cantidad de personas que migraron hacia Estados Unidos. ${ }^{5}$ Es decir, el gobierno aceptó de manera abierta que era un país expulsor, pero también de tránsito y destino de migrantes (Rosenthal, 2007: 3). Por tal motivo, el 26 de noviembre de 1998, se publicó en el Decreto número 95-98 del Congreso de la República la Ley de Migración. En este documento se encontraba un discurso de protección a los derechos humanos dirigido a las personas que estaban en Guatemala. También se establecieron categorías migratorias que permitían agilizar los trámites y procedimientos que requiriera la población nacional y extranjera con el objetivo de garantizar una migración documentada y ordenada, tal como menciona Rosenthal:

La Ley de Migración, Decreto 95-98 del Congreso de la República, garantiza un eficaz ordenamiento migratorio, regulando la entrada y salida de nacionales y extranjeros del territorio nacional, así como la permanencia de estos últimos dentro del mismo. De igual manera, establece que los extranjeros que ingresan al territorio nacional podrán hacerlo bajo las categorías de: a) No Residentes; y b) Residentes, clasificando a los primeros como personas en tránsito y turistas y visitantes, y a los segundos como residentes temporales o permanentes (2007: 10).

5 Maldonado Ríos indica que "la diáspora experimentada por la población guatemalteca durante la década de los noventa dirigida principalmente hacia los Estados Unidos de América, mantuvo una tendencia creciente. Según el censo de población de los Estados Unidos de América, la cifra de crecimiento de la comunidad inmigrante guatemalteca pasó de 63 073, en 1980, a 225 739, en 1990, mostrando una tasa de crecimiento intercensal de 13.6" (2010: 13). Asimismo, el autor señala que "a inicios de 1990, se estima que unos 225 mil guatemaltecos vivían en los Estados Unidos de América" (Maldonado Ríos, 2010: 13).
Aunado a lo anterior, con la implementación de esta ley se creó el Consejo Nacional de Migración, institución encargada de realizar cuatro funciones específicas:

1. Recomendar al Ministro de Gobernación la adopción de políticas y medidas convenientes para optimizar las acciones en materia migratoria;

2. Realizar estudios y emitir dictámenes sobre legislación y políticas migratorias, y hacer las recomendaciones pertinentes;

3. Sugerir la celebración, modificación o denuncia de convenios, tratados o cualquier arreglo internacional relacionados con materia migratoria; 4. Las normas operativas del Consejo y su régimen económico se regularán en el reglamento (Ley de Migración, 1998: 3).

Este instrumento jurídico estableció nuevos criterios para que las autoridades actuaran dependiendo del contexto que se presentara. Con la implementación de la Ley de Migración se generaron ciertas circunstancias positivas y también algunas no positivas.

Dentro de las mejoras, se facilitó la expedición de documentos a las empresas privadas para que pudieran entrar, salir o transitar por territorio guatemalteco (Caballeros, 2013: 146). De igual manera, se establecieron las funciones de la Dirección General de Migración (DGM), se definió el mandato institucional de este organismo y sus subdirecciones, y se establecieron las sanciones y facultades de las autoridades migratorias para regular, administrar, autorizar o negar la entrada y salida de personas al país (Caballeros, 2013: 146). Es decir, con dicho estatuto, las instituciones migratorias fueron respaldadas por un ámbito jurídico que antes no existía. Sin embargo, como señala Jorge Bustamante: "la actual Ley de migración contiene numerosas imprecisiones, lo que conlleva a que en numerosas ocasiones se produzcan irregularidades y abusos en contra de la población” (2009: 26). 
Por otra parte, al revisar de manera detenida este instrumento jurídico, se puede observar que su discurso se centra en la seguridad nacional y en la reactivación de la economía, no en la seguridad humana. ${ }^{6}$ Además de estos aspectos, no se encuentra una propuesta de resolución y resarcimiento de los daños estructurales y culturales que los conflictos armados internos ocasionaron, en especial, a la población migrante retornada. Por tal motivo, en 1999, las ciudadanas Julia González Deras y Rosa Solís López crearon MENAMIG, ${ }^{7}$ "instancia que facilita la articulación de esfuerzos de las instituciones, organizaciones y personas miembros para la atención de la problemática migratoria y defensa de los derechos humanos de la población migrante y sus familiares" (MENAMIG, 2015).

Es decir, ante la falta de respuesta por parte de las instituciones gubernamentales, las asociaciones civiles comenzaron a coordinarse e intentaron aportar acciones e investigaciones para disminuir los problemas que se suscitaron en el país centroamericano durante el periodo de posguerra. Este tipo de situaciones se observan en décadas posteriores.

6 Por ejemplo, en el artículo 87 se encuentra la definición de 'control migratorio', que puede entenderse como "la organización y coordinación de los servicios relativos a la entrada y salida de nacionales y extranjeros del territorio de la República mediante calificación de sus documentos y el estudio de los problemas que este movimiento origine" (Ley de Migración, 1998: 14). De igual manera, en el artículo 89 se considera ilegal la permanencia de una persona extranjera que se encuentre en alguna de las siguientes condiciones: "1) Haber ingresado al país por un lugar no habilitado para tal efecto; 2) Haber ingresado sin someterse al control migratorio; 3) No cumplir con las disposiciones que regulen el ingreso o la permanencia de conformidad con lo preceptuado en la presente ley y su reglamento; y, 4) Permanecer en el país después de vencido el plazo autorizado" (Ley de Migración, 1998: 14).

7 Los objetivos de MENAMIG son: 1) "Promover, defender y divulgar los derechos humanos y dignidad de la población migrante y sus familiares"; y 2) "Incidir en la formulación y ejecución de las políticas públicas y en la educación del marco legal en materia migratoria nacional e internacional, de acuerdo a las causas, impactos y consecuencias de la migración" (2015).

\section{Guatemala, siglo XXI}

En los primeros años del siglo XXI, la población guatemalteca enfrentaba las secuelas de la posguerra, como desempleo, instituciones gubernamentales débiles, inflación en los productos de la canasta básica, mayores índices de inseguridad, violencia generalizada y corrupción. Estas problemáticas afectaban y dejaban en condición de vulnerabilidad a diversas comunidades, principalmente indígenas, quienes, en algunos casos, tomaban la decisión de salir de su país para buscar mejores oportunidades de vida.

Ante esta situación, el 5 de noviembre de 2002, el gobierno guatemalteco implementó el PNR — después de nueve años de presentar la primera propuesta—, documento elaborado con "el propósito de reparar, resarcir, restituir, indemnizar, asistir, rehabilitar y dignificar a las víctimas del enfrentamiento armado" (PNR, 2002: 3). En el texto se establecieron cuatro medidas: "la restitución material, la indemnización económica, la reparación psicosocial y rehabilitación y la dignificación de las víctimas" (PNR, 2002: 3).

Con la implementación del PNR, el gobierno pretendía garantizar estándares de bienestar básicos a sus ciudadanos — vivienda, alimentación, empleo, sueldos, seguridad pública, acceso a los servicios de salud y otros-que, a su vez, permitieran ejercer el derecho a no emigrar o a quedarse. Por tanto, el PNR tenía como objetivo crear un componente jurídico para pactar una reconciliación nacional mediante la justicia. Sin embargo, esto no sucedió porque, como señala Paredes (2018), el programa tuvo pocos avances en el resarcimiento de las víctimas, pues a las personas no se les otorgó atención psicosocial, no se les incorporó a sus comunidades, no se les entregaron las tierras que les pertenecían y no se atendió a quienes buscaron refugio fuera de su país. En otras palabras: Guatemala tenía una población que se encontraba en condición de vulnerabilidad porque no existían avances en la 
resolución de sus problemáticas y, en consecuencia, las personas continuaban migrando. La falta de voluntad política por parte de los gobiernos para resolver esta situación derivó en la participación organizada de la sociedad civil, así como en la creación de institutos para servir a las comunidades de diferentes maneras. En febrero de 2005 nació el INCEDES, una asociación civil que tiene como misión:

fortalecer redes de pensamiento y acción para la promoción de cambios en las realidades sociales e institucionales que propician la movilidad humana en el sistema migratorio Centro-Norte América desde la perspectiva de derechos humanos, equidad de género, acceso a la justicia y desarrollo sostenible [De igual manera] promueve y contribuye en la construcción de una región centroamericana que garantiza: el 'derecho a no migrar' o 'derecho a quedarse' o sea gozar del bienestar y el desarrollo en el lugar donde se nace, y el 'derecho a migrar' en condiciones que garanticen la seguridad humana de las personas migrantes y sus familiares (INCEDES, 2014).

La creación de este organismo fue un importante logro porque gracias a las asociaciones civiles se visibilizó, de manera gradual, la incapacidad estatal e institucional para la resolución de problemáticas sociales —por ejemplo, en 2006 se estimaba que de los 12699780 guatemaltecos, un 50.9\% vivía en pobreza (López y Rivera, 2013: 9; Rosenthal, 2007: 5)—.

Además, como señalan López y Rivera, el gobierno guatemalteco no se ha ocupado en implementar y aplicar medidas para reducir los niveles de precariedad, sino que ha apostado por políticas de seguridad pública, como si fuera el único factor causante de la inestabilidad social, económica y política del país:
La construcción del Estado guatemalteco desde su origen excluyente, no sólo mantiene a gran cantidad de personas en pobreza, sino además ha generado condiciones de vulnerabilidad, y en el caso que nos ocupa, estas condiciones se están validando a través de políticas de securitización, administración de flujos migratorios, libre comercio, entre otros, que no afrontan la responsabilidad y obligación de garantizar y proteger los derechos de las personas migrantes y sus familiares (2013: 9).

En este sentido, el gobierno ha recibido presiones por medio de las acciones e investigaciones de activistas y asociaciones civiles para que se haga cargo de las responsabilidades que tiene con su ciudadanía. Así, en 2007 se creó -mediante el Decreto 46-2007- el CONAMIGUA, un:

ente nacional que coordina, define, supervisa y fiscaliza las acciones y las actividades de los órganos y las entidades del Estado tendientes a proteger y brindar asistencia y auxilio a los migrantes guatemaltecos y a sus familias en Guatemala, así como a los migrantes que se encuentran en el territorio nacional (Congreso de la República de Guatemala, 2007: 2).

Aunque la creación de dicho organismo representa un progreso en la atención a las personas migrantes guatemaltecas y no guatemaltecas, este ente coordinador y fiscalizador no ha tenido una buena administración desde su fundación, porque algunos de sus funcionarios no están capacitados en temas migratorios $y$, a veces, el presupuesto no es suficiente para llevar a cabo sus objetivos (Roldán A., 2017).

En consecuencia, Roldán A. (2017) menciona que los planes, programas y acciones en materia migratoria de este organismo han tenido un impacto mínimo en la sociedad, porque no se brinda una atención jurídica ni social a las personas 
que salen de su país. Asimismo, no se han implementado medidas de reinserción socioeconómica para quienes han sido deportados por las autoridades mexicanas y estadounidenses.

Llama la atención que la incapacidad operativa de las instituciones gubernamentales en materia migratoria haya hecho que las organizaciones civiles cobraran una gran importancia. En 2014, un grupo de personas que habían sido deportadas por las autoridades migratorias estadounidenses se enfrentó al problema de que, al regresar a su país, no existía ningún programa o asociación que garantizara su reinserción social y económica. Ante dicho inconveniente, algunos civiles fundaron la Asociación de Retornados Guatemaltecos (ARG), con el propósito de brindar apoyo y asistencia a la población deportada por las autoridades migratorias mexicanas y estadounidenses.

Cabe resaltar que la ARG es la única organización civil que atiende a los retornados y ofrece diversos servicios:

Se brinda asesoría, acompañamiento y seguimiento de casos especiales, a nivel administrativo, financiero, técnico y de vinculación laboral y educativa, incidiendo positivamente en la toma de decisión de las personas en la remigración o bien en la migración de sus familiares, a nivel público se incide en el personal operativo, y se da atención en procesos para la mejora de la atención integral (ARG, 2017: 1).

Estas acciones por parte de la ARG han impulsado que el sector privado también se interese por los migrantes que vuelven de Estados Unidos, pues quienes aprendieron la lengua inglesa pueden ser guiados para obtener un trabajo en diversos sectores económicos. En 2015, la Fundación Avina, Cities Alliance y algunas instituciones públicas implementaron el programa Guate Te Incluye, que tiene como objetivo "contribuir a la inclusión social y laboral de la población migrante retornada" (Fundación Avina, 2018). De acuerdo con los objetivos de la iniciativa, esto se puede realizar de dos maneras:

1. La primera es para un empleo formal digno, para el cual el migrante recibe orientación laboral, entre otros procedimientos.

2. La otra es para emprendimiento; en este sentido, se evalúan las habilidades empresariales, se les brinda asistencia técnica para el diseño e implementación de un plan y también inclusión financiera, entre otras asistencias (Fundación Avina, 2018).

Este programa es nuevo y todavía no existen datos para saber si ha tenido un impacto positivo o negativo durante su aplicación. Es necesario esperar a que se realicen estudios específicos sobre el tema para poder profundizar al respecto.

Tomando en cuenta estas iniciativas de asociaciones civiles y entidades privadas, se puede observar la débil o, en algunos casos, nula existencia de programas y acciones gubernamentales que atiendan a los migrantes. En este sentido, la voluntad de la población guatemalteca, así como de las empresas privadas, constituye un avance en este ámbito y, a la vez, visibiliza la necesidad de que el Estado comience a responsabilizarse en temas de derechos humanos y seguridad para que la migración sea una opción y el retorno se haga en condiciones dignas y con programas de reinserción socioeconómica.

Con base en este antecedente, el 18 de septiembre de 2016, el congreso aprobó el Código de Migración, un instrumento jurídico que deroga el Decreto 95-98, correspondiente a la Ley de Migración. Esta normativa establece un discurso integral de reconocimiento de los derechos humanos de la población guatemalteca y extranjera en materia migratoria, y estipula que "un migrante cuenta con derecho a moverse temporalmente por el territorio guatemalteco [y] es reconocido por la Constitución de la República, con posibilidad incluso de tener atención en salud, educación, 
asistencia en temas laborales, de asilo y de refugio" (Hernández, 2016). Con la aprobación de este documento, se creó el Instituto Guatemalteco de Migración (IGM), que tiene entre sus principales objetivos: regular la entrada y salida de nacionales y no-nacionales, registrar y contabilizar la cantidad de migrantes que se encuentran/ cruzan el país centroamericano, asistir a las personas con la emisión de pasaportes, entre otros. Con ello, por primera vez se contará con datos y cifras oficiales que después podrán ser utilizados para la sistematización y análisis de la información (Hernández, 2016; Hernández, 2019).

Actualmente, no se puede saber el impacto del código, ya que se "contempla un plazo de dos años para crear toda la institucionalidad necesaria, los traspasos de funciones y la implementación de un sistema migratorio coordinado" (Hernández, 2016). Será hasta la tercera década del siglo XXI cuando obtengamos información que nos permita determinar qué papel ha jugado el gobierno para solucionar los problemas estructurales que han motivado la migración de ciertos sectores de la población.

Por el momento, se puede observar que Guatemala enfrenta una etapa de posguerra donde las instituciones están debilitadas y los ciudadanos han tratado de solucionar los asuntos relativos a la migración. Sin embargo, se necesita trabajar de manera coordinada para lograr objetivos que sirvan para el bien común. De esta manera, migrar será una opción y no una consecuencia de los diversos conflictos sociales, culturales e históricos que han existido y persisten en el país centroamericano.

\section{ConcLusiones}

El gobierno guatemalteco debe garantizar niveles de bienestar básicos para que sus connacionales tengan el derecho y puedan decidir no emigrar. Este es un tema complejo, porque las autoridades no han hecho lo suficiente para unificar a la sociedad civil, instaurar la democratización del Estado y alcanzar una paz aceptada por las comunidades.

Dicha situación visibiliza los profundos problemas que existen en Guatemala y que, a su vez, han ocasionado que una parte de la ciudadanía no confíe en su gobierno. Esto se originó en la década de 1980, cuando el general Fernando Lucas García implementó la política conocida como Tierra Arrasada, cuyo objetivo era asesinar a toda persona que estuviera vinculada con los grupos guerrilleros. Desde ese momento, la ciudadanía no ha recibido un apoyo adecuado por parte de las instituciones públicas (Pérez Mendoza, 2016: 189-190).

Al término del conflicto armado interno, dichas instituciones se debilitaron por la falta de credibilidad de los ciudadanos y, también, por la falta de voluntad política de los servidores públicos. Ante estos aspectos, las promesas del gobierno han quedado en actos retóricos que no solucionan nada en temas sociales, políticos, económicos y migratorios (Monroy García, 2013: 84-85; Molden, 2014: 196-197).

En este contexto, las asociaciones civiles guatemaltecas han sido actores políticos destacados, porque desde el conflicto armado interno la Organización Mamá Maquín ha buscado el reconocimiento de los derechos humanos, la reunificación física y cultural de los indígenas, y la reinserción social de las personas refugiadas en México (Kauffer Michel, 2000: 10).

Cabe destacar que después de la firma de los Acuerdos de Paz (1996) distintas asociaciones han buscado atender el fenómeno migratorio desde la investigación y la acción. MENAMIG brinda atención jurídica y social a migrantes y a sus familiares; INCEDES investiga las diversas problemáticas de movilidad humana y migración, siempre abordando cada tema desde una perspectiva de equidad de género, derechos humanos y acceso a la justicia; ARG brinda asesoría y ayuda 
a quienes han sido deportados por las autoridades de Estados Unidos y, de forma conjunta con la Fundación Avina, trabaja para incluir laboralmente a las personas que cuentan con el dominio del idioma inglés (MENAMIG, 2015; INCEDES, 2014; ARG, 2017: 1).

Las organizaciones mencionadas han realizado enormes aportes a la investigación y defensa de los derechos humanos. Sin embargo, también se observa la falta de responsabilidad de las instituciones públicas y el gobierno en general, porque no existe un apoyo a la ciudadanía ni se busca resarcir los daños que se generaron durante y después de los conflictos armados internos (Hernández, 2016; Hernández 2019).

En conclusión, el gobierno guatemalteco, las asociaciones civiles y los diversos expertos en temas de migración y derechos humanos necesitan trabajar de manera coordinada para desarrollar y aplicar políticas públicas y migratorias que generen altos niveles de bienestar social; esto, con el objetivo de que la población de este país tenga el derecho a no emigrar. Con trabajo en equipo y verdadera voluntad política se pueden lograr importantes avances sociales que le permitan a la ciudadanía disfrutar de una seguridad humana.

\section{REFERENCIAS}

Archila, Haydeé (2015), "Unidas por la madre tierra”, en Memorial para la Concordia, Organización de Cooperación Alemana y DW Akademie, Mapeo de la Memoria, Guatemala, disponible en: http://mapeo.memorialparalaconcordia.org/article.php?id=123

Arias Sánchez, Oscar, Marco Vinicio Cerezo Arévalo, José Napoleón Duarte et al. (1986), Esquipulas I: el primer paso para el diálogo de paz, Guatemala, Fundación Esquipulas.

Armijo Canto, Natalia (2011), "Frontera sur de México: los retos múltiples de la diversidad”, en Natalia Armijo Canto (ed.), Migración y seguridad: nuevo desafío en México, México, Colectivo de Análisis de la Seguridad con Democracia, pp. 35-51.

Asociación de Retornados Guatemaltecos (ARG) (2017), Informe anual, Guatemala.

Bornschein, Dirk (2017), “Antecedentes: el caso de las migra- ciones en Guatemala, causas y cifras", Diálogo de Emergencia, quinta época, núm. 2, disponible en: http://www.flacso. edu.gt/dialogo/?p=1826

Bustamante, Jorge (2009), "VII. Recomendaciones", en Promoción y protección de todos los derechos humanos, civiles, políticos, económicos, sociales y culturales, incluido el derecho al desarrollo. Informe del Relator Especial sobre los derechos humanos de los migrantes, Sr. Jorge Bustamante. Adición. Misión a Guatemala (24 a 28 de marzo de 2008), Asamblea General de las Naciones Unidas, Guatemala, pp. 26-28, disponible en: https:/www.acnur.org/fileadmin/Documentos/ BDL/2009/7045.pdf

Caballeros, Álvaro (2013), Perfil Migratorio de Guatemala 2012, Guatemala, Organización Internacional para las Migraciones, disponible en: https://publications.iom.int/system/ files/pdf/mpguatemala_11july2013.pdf

Castillo, Manuel Ángel (2000) "Las políticas hacia la migración centroamericana en países de origen, de destino y de tránsito", Papeles de Población, vol. 6, núm. 24, pp. 133-157, disponible en: http://www.scielo.org.mx/scielo.php?script $=$ sci arttext\&pid=S1405-74252000000200007

Comisión para el Esclarecimiento Histórico (CEH) (1999), Guatemala, memoria del silencio, Guatemala, Oficina de Servicios para Proyectos de las Naciones Unidas, disponible en: http://www.centrodememoriahistorica.gov.co/descargas/guatemala-memoria-silencio/guatemala-memoriadel-silencio.pdf

Congreso de la República de Guatemala (2007), Ley del Consejo Nacional de Atención al Migrante de Guatemala, Decreto número 46-2007, Guatemala, Centro Nacional de Análisis y Documentación Judicial.

Corte Interamericana de Derechos Humanos (CIDH) (2018), Caso Coc Max y otros (Masacre de Xamán) vs. Guatemala. Sentencia de 22 de agosto de 2018 (Fondo, reparaciones y costas), Ciudad de San José, Costa Rica, Corte Interamericana de Derechos Humanos, disponible en: https://www. corteidh.or.cr/docs/casos/articulos/seriec_356_esp.pdf

Fernández, José Manuel (1991), “Integración social de los refugiados guatemaltecos en México y perspectivas de retorno", Cuadernos de Trabajo Social, núm. 4-5, pp. 27-41.

Fundación Avina (2018), "Guate Te Incluye”, Fundación Avina, Guatemala, disponible en: https://www.cepal.org/sites/ default/files/events/files/35_presentacion_guate_te_incluye_14_de_junio_2018.pdf

García Sánchez, Ernesto Eduardo y Héctor Josué Valdéz Rodas (2002), "Guatemala”, en Cristián Doña Reveco (ed), Informes nacionales sobre migración internacional en países de Centroamérica, Santiago de Chile, CEPAL/OIM/BID, pp. 117-156.

Goldman, Francisco (1999), "El asesinato alcanza al obispo", Letras Libres, México, 30 de septiembre de 1999, disponible en: https://www.letraslibres.com/mexico/el-asesinatoalcanza-al-obispo

Grupo Contadora (1986), Acta de Contadora para la Paz y la Cooperación en Centroamérica, Sistema de Integración Centroamericana, disponible en: https://www.sica.int/ documentos/acta-de-contadora-para-la-paz-y-la-cooperacion-en-centroamerica_1_6284.html

Hernández, Oswaldo J. (2016) “Código Migratorio: ¿Guatema- 
la como puente o como un muro más al sur?", en Plaza Pública, Guatemala, 8 de agosto de 2016, disponible en: https://www.plazapublica.com.gt/content/codigo-migratorio-guatemala-como-puente-o-como-un-muro-mas-al-sur

Hernández, Daniela (2019), "De Ley de Migración a Código de Migración”, Lexincorp Guatemala, disponible en: http:/lexincorp.com/de-ley-de-migracion-a-codigo-de-migracion/

Instituto Centroamericano de Estudios Sociales y Desarrollo (INCEDES) (2014), “¿Quiénes somos?”, en INCEDES, disponible en: https://www.incedes.org.gt/quienes.php

Kauffer Michel, Edith F. (2000), "Refugiados guatemaltecos en México: del refugio a la repatriación, del retorno a la integración”, Boletín de Migración Internacional, núm. 12, pp. 7-12.

Ley de Migración (1998), Decreto número 95-98, Guatemala.

López, Claudia V. y Danilo Rivera (2013), Aproximaciones de política migratoria para Guatemala, Guatemala, Grupo Articulador de la Sociedad Civil en Materia Migratoria, disponible en: http://www.url.edu.gt/PortalURL/ Archivos/100/Archivos/Aproximaciones\%20de\%20 Pol\%C3\%ADtica\%20P\%C3\%BAblica\%20Migratoria\%20Grupo\%20Articulador.pdf

Maldonado Ríos, Erick Mauricio (2010), Marco General y Descripción de Acciones del Estado de Guatemala en Materia Migratoria, Guatemala, Consejo Nacional de Atención al Migrante de Guatemala.

Mesa Nacional para las Migraciones en Guatemala (MENAMIG) (2015), "Un poco de historia y quienes somos", disponible en: http://www.menamig.org/historia/

Molden, Berthold (2014), Politicas sobre la historia en Guatemala. Historiografía, justicia de posguerra y resarcimiento (19962005), Guatemala, AVANCSO.

Monroy García, Juan José (2013), De la insurrección a la transición a la democracia en Centroamérica. Los casos de El Salvador, Guatemala y Nicaragua, México, UAEM.

Paredes, Luisa (2018) "Programa Nacional de Resarcimiento con pocos avances a 15 años de su creación”, en El Periódico, Guatemala, 8 de mayo de 2018, disponible en: https://elperiodico.com.gt/nacion/2018/05/08/programanacional-de-resarcimiento-con-pocos-avances-a-15-anosde-su-creacion/

Pérez Mendoza, Joel (2016), "México iun país de refugio? El caso de los refugiados guatemaltecos en Chiapas, 19811999”, en Mario Vázquez Olivera y Fabián Campos Hernández (coords.), México ante el conflicto centroamericano. Testimonio de una época, México, UNAM.

Proceso (2002), "Frontera sur: la incongruencia mexicana", en Proceso, México, 13 de julio de 2002, disponible en: https://www.proceso.com.mx/243339/frontera-sur-la-incongruencia-mexicana

Programa Nacional de Resarcimiento (PNR) (2002), "Programa Nacional de Resarcimiento. Naturaleza de la Organización", en Memoria Virtual Guatemala, disponible en: http://www.memoriavirtualguatemala.org/?q=es/programa-nacional-de-resarcimiento

Roldán A., Úrsula (2017), "iA quién le importa el Conamigua?", en Plaza Pública, Guatemala, 7 de abril de 2017, disponible en: https://plazapublica.com.gt/content/quienle-importa-el-conamigua
Rosenthal, Gert (2007), Política de protección, asistencia y atención al guatemalteco en el exterior, Guatemala, Ministerio de Relaciones Exteriores de Guatemala.

Soberanis, Catalina y Edgar Chamorro Marín (2016), "Los acuerdos de Esquipulas y su decisivo aporte a la paz, la democracia, la integración y el desarrollo de Centroamérica (su especial contribución al proceso de paz de Guatemala)", Guatemala, Fundación Esquipulas, disponible en: http://www.fundaesq.org/os-acuerdos-de-esquipulas-y-sudecisivo-aporte-a-la-paz-la-democracia-la-integracion-yel-desarrollo-de-centroamerica-su-especial-contribucion-a1-proceso-de-paz-de-guatemala/

Thesing, Josef (1999), La democracia en Guatemala, Guatemala, Instituto Centroamericano de Estudios Políticos.
Ian Yetlanezi Chávez Flores. Licenciado en Letras Latinoamericanas por la Universidad Autónoma del Estado de México (UAEM, México). Pasante de la Maestría en Humanidades por la UAEM. Ha sido asistente de investigación en el Centro de Investigaciones y Estudios Superiores en Antropología Social (CIESAS), México; formó parte del Policy and Institutional Research Program de la Universidad de Harvard y la fundación Mexikans; realizó una estancia de investigación en el INCEDES, Guatemala. Ha publicado en revistas del ITAM, la UNAM y la UAEM. Es fundador y director general de Más Literatura. 